\title{
Social Context and the Psychobiology of Posttraumatic Stress
}

\author{
SANDRO GALEA, ${ }^{a}$ RON ACIERNO, ${ }^{b}$ KENNETH RUGGIERO,${ }^{b}$ \\ HEIDI RESNICK, ${ }^{b}$ MELISSA TRACY,${ }^{a}$ AND DEAN KILPATRICK ${ }^{b}$ \\ ${ }^{a}$ Department of Epidemiology, University of Michigan School of Public Health, \\ Ann Arbor, Michigan, 48104, USA \\ ${ }^{b}$ National Crime Victims' Research and Treatment Center, Medical University of \\ South Carolina,Charleston, South Carolina, 29425 USA
}

\begin{abstract}
A growing body of research is identifying the molecular and genetic correlates of psychopathology and holds tremendous promise in suggesting the biologic mechanisms that may explain emergent posttraumatic stress disorder (PTSD) phenotypes. Another body of research has begun to consider how elements of the social context may influence the risk of PTSD. It is likely that the social context and molecular/genetic factors jointly determine the risk of PTSD and as such scientific inquiry that considers the interrelationship of these factors stands to advance the field. However, there are particular conceptual and methodologic challenges to conducting and designing studies that adequately assess both the social context and the biologic determinants of PTSD. Much of the current research exploring the biology of PTSD is conducted with highly selective samples that were recruited on the basis of strict phenotypic or medical history criteria. In contrast, population-based sampling represents an opportunity to obtain heterogenous samples that better represent the population distribution of relevant molecular, genotypic, and phenotypic parameters of interest. These sampling strategies also allow researchers to consider the role of the social context and in turn, how the social context influences the molecular determinants of PTSD. An example of our own work illustrates the feasibility of the population-based sampling approach.
\end{abstract}

KEYWORDS: posttraumatic stress; epidemiology; genetics; biology; social context

\section{INTRODUCTION}

A substantial body of work over the past two decades has elucidated the neuroendocrinologic correlates of posttraumatic stress symptoms. ${ }^{1}$ More recently,

Address for correspondence: Sandro Galea, M.D., DrPH., Department of Epidemiology, University of Michigan School of Public Health, 1214 S. University, Ann Arbor, MI 48104. Voice: 734-647-9741; fax: 734-998-0006.

e-mail: sgalea@umich.edu

Ann. N.Y. Acad. Sci. 1071: 231-241 (2006). (C) 2006 New York Academy of Sciences.

doi: 10.1196/annals.1364.018 
research that explores the genetic determinants of psychopathology in general, ${ }^{2}$ and of posttraumatic stress disorder (PTSD) in particular, has shed new light on the etiology of PTSD and related disorders. ${ }^{3}$ As our understanding of PTSD grows, it is clear that there is a growing role for research that studies the biologic determinants of PTSD. Delineating the precise genetic and molecular determinants of PTSD holds promise for early identification of those at risk for PTSD and for the development of pharmacologic interventions that can prevent PTSD or ameliorate PTSD symptoms.

As our appreciation of the endogenous determinants of PTSD has grown, so also has our appreciation of the exogenous determinants of PTSD. Recent reviews have consolidated our understanding of the individual risk factors for PTSD. ${ }^{4}$ Complementing this, a growing body of research is now starting to shed light on mechanisms through which group-level factors influence both the development and course of psychopathology. Exposition of the role of contextual determinants of PTSD holds promise for the development of population-based health interventions that can reduce vulnerability to PTSD or mitigate the consequence of this disorder. ${ }^{5}$ However, biologic research and epidemiologic inquiry into the role of social context have evolved separately with very few studies considering how social context, endocrinology, and biology may interact to influence the risk and course of PTSD. In this article we will briefly discuss $(a)$ the potential role of social context as a determinant of PTSD, (b) the potential relationship between contextual and biologic determinants of PTSD, $(c)$ the challenges involved in considering the joint contributions of social context and biology to PTSD, and $(d)$ potential epidemiologic approaches to the study of social context and the psychobiology of PTSD, focusing as an example on a recent study our group has completed.

\section{Social Context and Health}

Several authors have advanced multilevel conceptual frameworks that describe how risk factors for disease extend beyond individual biology or behavior and include the circumstances that shape this behavior. For example, Kaplan proposed a conceptual framework, which posits that social and economic policies influence local neighborhood characteristics that in turn shape living conditions and social relationships that influence individual risk behaviors. ${ }^{6}$ Therefore, social contextual factors (also referred to as "macrolevel" or "upstream" factors) are exogenous factors that are not properties of the individual per se, yet may shape both individual behavior and risk for disease.

Most of the empiric work demonstrating associations between social context and health has focused on physical health. For example, community poverty appears to be a determinant of several health-related outcomes including healthrelated behaviors, birth outcomes, adult physical health, coronary heart disease, and mortality even after accounting for individual-level factors. ${ }^{7-11}$ Other 
work shows that living in socially disordered communities, characterized by high levels of noise, litter, crime, vandalism, graffiti, and abandoned buildings, may result in persons being less likely to engage in physical activities ${ }^{12}$ and hence, high rates of obesity. Similarly, living in poor quality built environments may diminish the functional status of older adults. ${ }^{13}$

Although the body of work demonstrating associations between social context and mental health is much smaller by comparison, this area of research is growing. Two recent studies show that living in a neighborhood characterized by poor quality built environment is associated with greater risk of depression. ${ }^{14,15}$ Chronic exposure to threatening conditions faced by individuals in deprived communities engenders psychological responses that may directly lead to greater risk of psychopathology. ${ }^{16-18}$ Another study in this area demonstrates that social disorganization at the neighborhood level is associated with greater likelihood of depressive symptoms. ${ }^{19}$ Other work has shown that living in more deprived neighborhoods is associated with higher incidence of nonpsychotic disorders. ${ }^{20}$

\section{Social Context and Biology}

Most studies concerned with genetic determinants of disease have focused on gene-disease associations. Eighty-six percent of the Human Genome Epidemiology Network papers in one recent review were concerned specifically with gene-disease associations. ${ }^{21}$ However, recent studies suggest that genetic influences may also modify the relation between exposure to environmental stressors and psychiatric phenotypes. For example, work by Caspi and colleagues demonstrates that a particular polymorphism in the promotor region of the serotonin transporter gene was associated with risk (the two "long" alleles with lower risk, the two "short" alleles with higher risk) for depression symptoms, probability of major depressive episode, and probability of suicidal ideation or attempts given exposure to stressful life events. ${ }^{22}$ Other published examples of gene-environment interaction in the psychiatric literature have focused on the role of environmental factors, such as child maltreatment and cannabis use. ${ }^{23-26}$

Therefore, "environmental" factors may interact with gene-disease associations and must be considered in order to fully understand the biologic mechanisms that explain individual risk for PTSD. However, the existing literature remains limited in the range of contextual factors that have been considered empirically. Specifically, existing work considering gene-environment interactions has focused on behaviors and individual experiences or exposures (e.g., maltreatment, stressful life events) as the relevant "environmental" factors of interest. While these studies have begun to illustrate how factors exogenous to the individual interact with endogenous genetic determinants of disease, they have not considered how the macrolevel social context may interact with endogenous determinants of PTSD. 
Yet, there are several reasons why the joint consideration of features of social context and molecular/genetic determinants of PTSD may be fruitful. First, and centrally, social context is inescapable in any consideration of PTSD. PTSD is linked explicitly to traumatic event exposure. Traumatic event exposure in turn is clearly a socially patterned event. Disadvantaged populations are at greater risk for traumatic event exposure than other populations, ${ }^{27}$ and there is an abundance of evidence that specific contextual characteristics, including, for example, social capital are risks for exposure to traumatic events. ${ }^{28}$ Disasters are a useful reminder of the role of context in shaping risk of psychopathology. In the context of specific disasters, such as the Gulf Coast hurricanes of 2005 , the role played by social context (e.g., poverty, racial/ethnic segregation) was self-evident and is clearly difficult to avoid in any understanding of the consequences of these events.

Second, there is substantial heterogeneity in documented associations between context and risk of disease. As noted by Moffitt and colleagues "... it seems reasonable to suggest that whenever there is variation among human's psychological reactions to a major environmental pathogen for mental disorder, [gene-environment interactions] must be expected to some degree..." (p. 473). ${ }^{2}$ Proximal variables (e.g., individual behavior or genes) undoubtedly play a role in mediating the relationship between social context and risk of disease but also likely modify some specific gene-disease associations. Therefore, full explication of the role of context must include an understanding of individual mediators and effect modifiers, including both individual behaviors and risk factors and molecular and genetic determinants of PTSD psychobiology.

Third, at the population level, the contribution of social context to PTSD phenotypic expression may far outweigh the contribution of any given molecular or genotypic determinants. The magnitude of relative risk of disease conferred by social context is likely to be far less than that conferred by individual or biologic risk factors. However, the ubiquity of exposure to social contextual variables suggests that these factors will play a substantial role in determining the population distribution of psychopathology. For example, in a Danish population-based study, having a mother or father or sibling with schizophrenia was associated with a seven- to nine-fold increased risk of developing the disease, whereas the highest level of exposure to urbanicity was associated with a 2.4-fold increase in risk. ${ }^{29}$ The population attributable fraction, however, reverses the importance of these factors. A family history of schizophrenia accounted for $5.5 \%$ of cases, whereas urban place of birth accounted for $34.6 \%$. This is because few individuals have a family history of schizophrenia, whereas many people are born and raised in cities. Therefore, contextual variables may account for substantial interindividual heterogeneity in risk of psychopathology that, at the population level, may be critical to understanding population distribution of disease. 


\section{CHALLENGES IN STUDYING CONTEXT AND THE PSYCHOBIOLOGY AND PTSD}

The paucity of extant work that has explored the relationship among context, individual factors, biologic factors, and risk of PTSD in our estimation is predicated not only on a limited appreciation of the importance of considering context and biology conjointly, but also on substantial practical challenges that researchers interested in such studies face. There are challenges along both conceptual and methodologic grounds.

The key conceptual challenge facing such work lies in accurately identifying the relevant elements of social context, the mechanisms that may link social context to psychobiology, and the specific molecular or genetic determinants relevant to a particular mechanism. Unfortunately, our knowledge of the relative role of different contextual factors remains nascent, as does our knowledge of the potential relative contribution of different genes. Studies that attempt to explore the conjoint relationship between features of context and molecular or genetic determinants need to specify testable hypotheses that rest on our best available knowledge. Testable hypotheses that will advance the field are improved by specificity, including the specification of the role of variables at multiple levels and the consideration of potential confounders or mediators of the proposed relations. However, this may prove to be particularly challenging given our limited understanding of the potential mechanisms that link context, individual experiences, and biology. Conceptual work, predicated on an understanding of potential social and biologic mechanisms can go a long way to providing information that can guide specific inquiry into the role of context and biology in shaping risk of PTS.

There are also particular methodologic challenges facing investigators who are considering such empiric study. Related to the conceptual challenges noted above, specification of precise social contextual constructs may prove challenging. There have been three approaches adopted in the literature considering how social context may influence mental health. These include $(a)$ asking participants to describe conditions in their counties or communities (e.g., Ref. 30); (b) aggregating data "up" from the individual to the community level (e.g., Ref. 31); and (c) collecting archival data that reflect collective constructs (e.g., Ref. 32). All these methods rely on a particular specification of specific contextual constructs but all embed particular assumptions and may have implications for inference that can be drawn from particular studies. Therefore, the careful specification of relevant contextual constructs, predicated on well-developed a priori hypotheses about potential mechanistic relations, is critical for replicability of studies whose results contribute to the general body of knowledge.

A second methodologic challenge, also linked to the contextual challenges discussed here, pertains to the causal inference that may be drawn from 
TABLE 1. Characteristics of persons who did and did not return biological sample

\begin{tabular}{|c|c|c|c|c|c|c|c|}
\hline & \multirow{2}{*}{\multicolumn{2}{|c|}{ Total }} & \multicolumn{2}{|c|}{$\begin{array}{l}\text { Persons who } \\
\text { returned sample }\end{array}$} & \multicolumn{2}{|c|}{$\begin{array}{l}\text { Persons who did not } \\
\text { return sample }\end{array}$} & \multirow{3}{*}{$\begin{array}{c}\text { chi- } \\
\text { square } \\
P \text {-value }\end{array}$} \\
\hline & & & \multirow{2}{*}{$\begin{array}{l}N \\
\text { returned }\end{array}$} & \multirow{2}{*}{$\begin{array}{l}\% \\
\text { returnec }\end{array}$} & \multirow{2}{*}{$\begin{array}{c}N \\
\text { ed returned }\end{array}$} & \multirow{2}{*}{$\begin{array}{c}\% \\
\text { returned }\end{array}$} & \\
\hline & $N$ & $\%$ & & & & & \\
\hline Total & 1,543 & & 636 & 41.2 & 907 & 58.8 & \\
\hline \multicolumn{8}{|l|}{ Age } \\
\hline $18-24$ & 25 & 1.6 & 11 & 44.0 & 14 & 56.0 & 0.009 \\
\hline $25-34$ & 72 & 4.7 & 22 & 30.6 & 50 & 69.4 & \\
\hline $35-44$ & 112 & 7.4 & 36 & 32.1 & 76 & 67.9 & \\
\hline $45-59$ & 204 & 13.4 & 73 & 35.8 & 131 & 64.2 & \\
\hline$\geq 60$ & 1,107 & 72.8 & 489 & 44.2 & 618 & 55.8 & \\
\hline \multicolumn{8}{|l|}{ Gender } \\
\hline Male & 552 & 35.9 & 230 & 41.7 & 322 & 58.3 & 0.877 \\
\hline Female & 984 & 64.1 & 406 & 41.3 & 578 & 58.7 & \\
\hline \multicolumn{8}{|l|}{ Race } \\
\hline White & 1,296 & 85.3 & 571 & 44.1 & 725 & 55.9 & $<0.001$ \\
\hline African American & 96 & 6.3 & 25 & 26.0 & 71 & 74.0 & \\
\hline Hispanic & 80 & 5.3 & 23 & 28.8 & 57 & 71.3 & \\
\hline Asian/Pacific Islander & 13 & 0.9 & 5 & 38.5 & 8 & 61.5 & \\
\hline Native American & 23 & 1.5 & 5 & 21.7 & 18 & 78.3 & \\
\hline Multiracial & 11 & 0.7 & 3 & 27.3 & 8 & 72.7 & \\
\hline \multicolumn{8}{|l|}{ Income } \\
\hline$>\$ 100,000$ & 103 & 7.9 & 36 & 35.0 & 67 & 65.0 & 0.275 \\
\hline$\$ 50,001-\$ 100,000$ & 266 & 20.3 & 122 & 45.9 & 144 & 54.1 & \\
\hline$\$ 35,001-\$ 50,000$ & 261 & 19.9 & 115 & 44.1 & 146 & 55.9 & \\
\hline$\$ 15,001-\$ 35,000$ & 426 & 32.5 & 192 & 45.1 & 234 & 54.9 & \\
\hline$\leq \$ 15,000$ & 255 & 19.5 & 103 & 40.4 & 152 & 59.6 & \\
\hline \multicolumn{8}{|l|}{ Marital status } \\
\hline Married & 798 & 52.1 & 344 & 43.1 & 454 & 56.9 & 0.325 \\
\hline Divorced & 209 & 13.6 & 80 & 38.3 & 129 & 61.7 & \\
\hline Separated & 27 & 1.8 & 8 & 29.6 & 19 & 70.4 & \\
\hline Widowed & 327 & 21.3 & 141 & 43.1 & 186 & 56.9 & \\
\hline Never married & 110 & 7.2 & 39 & 35.5 & 71 & 64.5 & \\
\hline Unmarried couple & 62 & 4.0 & 23 & 37.1 & 39 & 62.9 & \\
\hline \multicolumn{8}{|l|}{ Social support } \\
\hline Low & 588 & 38.6 & 246 & 41.8 & 342 & 58.2 & 0.383 \\
\hline Medium & 466 & 30.6 & 201 & 43.1 & 265 & 56.9 & \\
\hline High & 469 & 30.8 & 182 & 38.8 & 287 & 61.2 & \\
\hline \multicolumn{8}{|l|}{$\begin{array}{l}\text { Any smoking since } \\
\text { hurricanes }\end{array}$} \\
\hline Yes & 310 & 20.1 & 125 & 40.3 & 185 & 59.7 & 0.707 \\
\hline No & 1,229 & 79.9 & 510 & 41.5 & 719 & 58.5 & \\
\hline \multicolumn{8}{|l|}{ Overall health } \\
\hline Poor & 106 & 6.9 & 44 & 41.5 & 62 & 58.5 & 0.218 \\
\hline Fair & 223 & 14.5 & 76 & 34.1 & 147 & 65.9 & \\
\hline Good & 375 & 24.4 & 163 & 43.5 & 212 & 56.5 & \\
\hline Very good & 482 & 31.3 & 201 & 41.7 & 281 & 58.3 & \\
\hline Excellent & 353 & 22.9 & 150 & 42.5 & 203 & 57.5 & \\
\hline
\end{tabular}


TABLE 1. Continued.

\begin{tabular}{|c|c|c|c|c|c|c|c|}
\hline & \multirow{2}{*}{\multicolumn{2}{|c|}{ Total }} & \multicolumn{2}{|c|}{$\begin{array}{l}\text { Persons who } \\
\text { returned sample }\end{array}$} & \multicolumn{2}{|c|}{$\begin{array}{l}\text { Persons who did not } \\
\text { return sample }\end{array}$} & \multirow{3}{*}{$\begin{array}{c}\text { chi- } \\
\text { square } \\
P \text {-value }\end{array}$} \\
\hline & & & \multirow{2}{*}{$\begin{array}{l}N \\
\text { returned }\end{array}$} & \multirow{2}{*}{$\begin{array}{c}\% \\
\text { returned }\end{array}$} & \multirow{2}{*}{$\begin{array}{l}N \\
\text { returned }\end{array}$} & \multirow{2}{*}{$\begin{array}{c}\% \\
\text { returned }\end{array}$} & \\
\hline & $N$ & $\%$ & & & & & \\
\hline \multicolumn{8}{|c|}{$\begin{array}{l}\text { Lifetime traumas } \\
\text { before hurricanes }\end{array}$} \\
\hline 0 & 498 & 32.3 & 217 & 43.6 & 281 & 56.4 & 0.021 \\
\hline 1 & 550 & 35.6 & 201 & 36.5 & 349 & 63.5 & \\
\hline $2+$ & 495 & 32.1 & 218 & 44.0 & 277 & 56.0 & \\
\hline \multicolumn{8}{|c|}{ Prior trauma with fear } \\
\hline No & 907 & 58.8 & 394 & 43.4 & 553 & 61.0 & 0.697 \\
\hline Yes & 636 & 41.2 & 242 & 38.1 & 354 & 55.7 & \\
\hline \multicolumn{8}{|c|}{$\begin{array}{l}\text { Exposure to Florida } \\
\text { hurricanes }\end{array}$} \\
\hline No & 839 & 54.4 & 347 & 41.4 & 492 & 58.6 & 0.903 \\
\hline Yes & 704 & 45.6 & 289 & 41.1 & 415 & 58.9 & \\
\hline \multicolumn{8}{|c|}{ PTSD in past } \\
\hline $6 \mathrm{mo}$ & & & & & & & \\
\hline No & 1,462 & 94.8 & 602 & 41.2 & 860 & 58.8 & 0.887 \\
\hline Yes & 81 & 5.3 & 34 & 42.0 & 47 & 58.0 & \\
\hline \multicolumn{8}{|c|}{$\begin{array}{l}\text { Depression in past } \\
6 \text { months }\end{array}$} \\
\hline No & 1,437 & 93.1 & 587 & 40.8 & 850 & 59.2 & 0.278 \\
\hline Yes & 106 & 6.9 & 49 & 46.2 & 57 & 53.8 & \\
\hline \multicolumn{8}{|c|}{$\begin{array}{l}\text { Generalized anxiety in } \\
\text { past } 6 \text { months }\end{array}$} \\
\hline No & 1,451 & 94.0 & 595 & 41.0 & 856 & 59.0 & 0.501 \\
\hline Yes & 92 & 6.0 & 41 & 44.6 & 51 & 55.4 & \\
\hline
\end{tabular}

studying social context as a determinant of PTSD. Contextual variables must influence individual health through pathways that involve more proximal, individual, and biologic variables. Hence, plausible causal inference requires the explicit explication of these pathways, complicating the researcher's task.

A third challenge involves the recruitment of adequate samples for the purposes of studying the joint role of context and psychobiology of PTSD. Most biologic research currently makes use of small, typically volunteer samples. However, studying the role of context requires the recruitment of samples that are representative of the general population and that are heterogenous for the contextual variables of interest. This then requires the methodologic combination of population-based sampling and biologic specimen collection that is not customary in either population-based or biologic research at the moment. In addition, such studies need to be designed to have sufficient statistical power available to detect both associations across levels of influence between contextual variables and risk of PTSD and also interactions between context and 
biology in determining PTSD. This necessitates sample sizes that are substantially larger than the samples that have typically been employed in biologic studies.

Epidemiologic approaches may help consider the role of context. We will illustrate briefly, by example, the feasibility of designing studies that may be used for the purposes of considering variables at multiple levels as determinants of PTSD.

The recruitment of large samples, with a wide range of environmental exposures and phenotypes, is necessary for the purposes of testing geneenvironment interactions. We have recently completed a study that aims to understand the determinants of psychopathology in the aftermath of the 2004 hurricanes in Florida that illustrates how population-based sampling can be effectively coupled with collection of biologic specimens for the eventual purpose of gene-environment hypothesis testing.

Briefly, psychological data for this study were collected from a sample of 1543 adults aged 18 years and older residing in households with telephones in Florida counties that were in the direct path of one or more of the 2004 hurricanes. The original sampling frame consisted of the 38 Florida counties that were exposed to hurricane force winds, ${ }^{33}$ but this was subsequently reduced to 33 counties after we terminated sampling from five counties (Bay, Broward, Holmes, St. Johns, and Washington) for which a relatively small proportion of the area and population experienced hurricane strength winds (cases from these five counties were not included in the final sample). The sampling frame also included an oversample of adults aged 60 years and more in order to address research questions specific to older adults as part of another study.

Random digit dial techniques were used to screen households for eligibility, and in instances where multiple eligible participants were present, the most recent birthday method was used to select the respondent. Interviews were conducted between April 5 and June 12, 2005. Informed consent was obtained verbally from participants and each participant was mailed a debriefing letter explaining the purposes of the study and providing investigator contact information. Up to five attempts were made to contact an adult at each telephone number. The overall cooperation rate (i.e., [completes + screenouts] divided by [completes + screen-outs + refusals before screen + qualified refusals]) was $70 \%$. The cooperation rate among eligible individuals (i.e., completes divided by [completes + qualified refusals]) was $81 \%$.

In addition to collecting information about county of residence (which will eventually be used for the purposes of considering the features of counties as potential determinants of psychopathology) and survey information about individual characteristics that may be determinants of PTSD, all participants were also invited to mail saliva samples, using prepaid packages, for the purposes of genetic testing. Participants were remunerated $\$ 10$ for participating in the interview and another $\$ 10$ for returning a saliva sample. 
As shown in TABLE 1, 636 (41.2\%) participants returned their saliva samples within 1 month of study completion. Participants who did provide saliva samples were more likely to be older $(P=0.009)$ and non-Hispanic $(P<0.001)$ than those who did not. However, return rates for biologic samples did not differ with respect to: psychopathology (PTSD, major depression, and generalized anxiety), characteristics of recent hurricane exposure, participant's prior exposure to severe (PTSD criterion A) life stressors, gender, or marital status. Therefore, although there may be some sociodemographic determinants of participation in a low-effort biologic specimen collection in the general population, likelihood of participation does not appear to confound assessment of studies assessing traumatic event exposure and psychiatric phenotypes. More specifically, there were no differences in rate of return of biologic samples in terms of those sociological variables directly implicated in PTSD, including comorbid diagnoses.

In addition, preliminary genotypic analyses with a subsample of 543 Caucasian participants in this study show that $30.9 \%$ of participants have longlong genotype for the SLC6A4 (5-HTT) serotonin promotor polymorphism, $53.8 \%$ have short-long genotype, and $15.3 \%$ short-short genotype for an overall 's' allele of approximately $42 \%$. This compares very favorably with a wellestablished cohort of 847 Caucasians collected by Caspi et al. ${ }^{22}$; in this cohort genotypic frequency for the SLC6A4 polymorphism are 31\% long-long, 51\% short-long, and $18 \%$ short-short, suggesting an overall 's' allele frequency of $43 \%$.

This example provides a simple illustration of recruitment of general population samples that may offer the opportunity to study how interactions between contextual and genetic factors determine population rates of PTSD and other forms of psychopathology.

\section{CONCLUSION}

Although growing bodies of work are casting light on features of the social context and molecular/biologic factors that are determinants of PTSD, there has been very little research that has explored how social context and biology jointly influence the risk of PTSD. There is ample theoretical and empirical evidence to suggest that social context is an important determinant of PTSD and that it may influence the relationship between specific genetic and molecular factors and the risk of PTSD. However, there are substantial challenges to conducting such research, including conceptual and methodologic hurdles that need to be overcome in order to make drawing of generalizable causal inference from such studies possible. Population-based sampling may feasibly collect information from multiple levels and provide representative epidemiologic samples that can be used to assess multilevel hypotheses about the joint role of context and biologic factors as determinants of PTSD. 


\section{REFERENCES}

1. Yehuda, R. 2002. Post-traumatic stress disorder. N. Engl. J. Med. 346: 108-114.

2. MoffitT, T.E. \& A. CASPI, et al. 2005. Strategy for investigating interactions between measured genes and measured environments. Arch. Gen. Psychiatry 62: 473-481.

3. Segman, R.H. \& A.Y. Shalev. 2003. Genetics of posttraumatic stress disorder. CNS Spectrums. 8: 693-698.

4. BREWIN, C.R. \& B. ANDREws, et al. 2000. Meta-analysis of risk factors for posttraumatic stress disorder in trauma-exposed adults. J. Consult. Clin. Psychol. 68: 748-766.

5. Galea, S. \& C. Hadley. 2006. Mitigating the consequences of disasters: an ecologic perspective. In Health Promotion and Practice. S. SHEInfELd Gorin \& J. ARnold, Eds.: 427-444. Josey-Bass. San Francisco, CA.

6. KAPLAN, G.A. 1999. What is the role of the social environment in understanding inequalities in health? Ann. N. Y. Acad. Sci. 896: 116-119.

7. Diez-RouX, A.V. 2001. Investigating neighborhood and area effects on health. Am. J. Public Health 91: 11783-11789.

8. Pickett, K.E. \& M. Pearl. 2001. Multilevel analyses of neighborhood socioeconomic context and health outcomes: a critical review. J. Epidemiol. Community Health 55: 111-122.

9. Yen, I.H. \& G.A. Kaplan. 1999. Neighborhood social environment and risk of death: multilevel evidence from the Alameda county study. Am. J. Epidemiol. 149: 898-907.

10. Diez-RouX, A.V. \& F.J. NiETo, et al. 1997. Neighborhood environments and coronary heart disease: a multilevel analysis. Am. J. Epidemiol. 146: 48-63.

11. Waitzman, N.J. \& K.R. Smith. 1998. Phantom of the area: poverty-area residence and mortality in the United States. Am. J. Pub. Health 88: 973-976.

12. LaGrange, R.L. \& K.F. Ferraro, et al. 1992. Perceived risk and fear of crime: role of social and physical incivilities. J. Res. Crime Delinquin. 29: 311334.

13. Balfour, J.L. \& G.A. KaPlan. 2002. Neighborhood environment and loss of physical function in older adults: evidence from the Alameda county study. Am. J. Epidemiol. 155: 507-515.

14. Galea, S. \& J. Ahern, et al. 2005. Urban built environment and depression: a multilevel analysis. J. Epidemiol. Community Health 59: 822-827.

15. WeICH, S. \& M. BlANCHARD, et al. 2002. Mental health and the built environment: cross-sectional survey of individual and contextual risk factors for depression. Br. J. Psychiatry 180: 428-433.

16. Ross, C. \& J. Mirowsky. 2001. Neighborhood disadvantage, disorder and health. J. Health Soc. Behav. 42: 258-276.

17. Fremont, A. \& B. Chloe. 2000. Social and psychological factors, physiological processes, and physical health. In The Handbook of Medical Sociology. C.E. Bird, P. Conrad, et al. Eds.: 334-352. Prentice Hall. Upper Saddle River, NJ.

18. McEvew, B.S. 2000. Allostasis and allostatic load: implications for neuropsychopharmacology. Neuropsychopharmacology 22: 108-124.

19. LATKIn, C.A. \& A.D. CuRRY. 2003. Stressful neighborhoods and depression: a prospective study of the impact of neighborhood disorder. J. Health Soc. Behav. 44: $34-44$. 
20. Driessen, G. \& N. Gunther, et al. 1998. Share social environment and psychiatric disorder: a multilevel analysis of individual and ecological effects. Soc. Psychiatry Psychiatr. Epidemiol. 33: 606-612.

21. Khoury, M.J. \& R. Millikan, et al. 2004. The emergence of epidemiology in the genomics age. Intl. J. Epidemiol 33: 936-944.

22. CASPI, A. \& J. McClay, et al. 2002. Role of genotype in the cycle of violence in maltreated children. Science 297: 851-853.

23. Foley, D.L. \& L.J. EAVES, et al. 2004. Childhood adversity, monoamine oxidase A genotype, and risk for conduct disorder. Arch. Gen. Psychiatry 61: 738-744.

24. CASPI, A. \& K. Sugden, et al. 2003. Influence of life stress on depression: moderation by a polymorphism in the 5-HTT gene. Science 18: 386-389.

25. Eley, T.C. \& K. SugDEN, et al. 2004. Gene-environment interaction analysis of serotonin system markers with adolescent depression. Mol. Psychiatry 9: 908915.

26. Kaufman, J. \& B. YAnG, et al. 2004. Social supports and serotonin transporter gene moderate depression in maltreated children. PNAS 101: 17316-17321.

27. HeIlemanN, M.V. \& F.S. KURY, et al. 2005. Trauma and posttraumatic stress disorder symptoms among low income women of Mexican descent in the United States. J. Nerv. Ment. Dis. 193: 665-672.

28. Silversides, J.A. \& A. GibSON, et al. 2005. Social deprivation and childhood injuries in north and west Belfast. Ulster Med. J. 74: 22-28.

29. Mortensen, P.B. \& C.B. Pdersen, et al. 1999. Effects of family history and place and season of birth on the risk of schizophrenia. N. Engl. J. Med. 340: 603-608.

30. HANSON, R.F. \& D.G. KilPATRICK, et al. 1995. Los Angeles county after the 1992 civil disturbances: degree of exposure and impact on mental health. J. Consult. Clin. Psychol. 63: 987-996.

31. Perilla, J.L. \& F.H. NorRis, et al. 2002. Ethnicity, culture and disaster response: identifying and explaining ethnic differences in PTSD six months after hurricane Andrew. J. Soc. Clin. Psychol. 21: 20-45.

32. NorRis, F.H. \& J.F. PhIFER, et al. 1994. Individual and community reaction to the Kentucky floods: findings from a longitudinal study of older adults. In Individual and Community Responses to Trauma and Disaster: The Structure of Human Chaos. R.J. Ursano, B.G. McCAUGHeY, et al. Eds.: 348-400. Cambridge University Press. Cambridge, UK.

33. NOAA. 2004. Accessed: February, 2005, from: http://www.palmbeachpost. com/storm/content/weather/special/storm/2004/atlantic. 